\title{
Model Pendidikan Guru Berbasis Ke-Bhinekaan Budaya di Indonesia
}

\author{
Al Musanna \\ Email: win_moes@yahoo.co.id / winmoes78@gmail.com
}

\begin{abstract}
Abstrak: Pendidikan guru di Indonesia seyogianya memberi perhatian dalam revitalisasi nilai dan budaya lokal sebagai fondasi pengembangannya, hal ini berdasarkan kenyataan bahwa Indonesia merupakan salah satu negara yang paling pluralistik ditinjau dari suku bangsa dan budaya. Praksis pendidikan guru tanggap budaya atau culturally responsive pedagogy, memberi harapan sebagai jalan keluar untuk menjembatani revitalisasi budaya lokal dan peningkatan relevansi pendidikan guru di tanah air. Penekanan pada pendidikan guru tanggap budaya didasari kenyataan masih terkesampingkannya budaya lokal atau kearifan lokal dalam kebijakan dan kurikulum pendidikan guru di tanah air.
\end{abstract}

Kata kunci: Pendidikan Guru, Budaya Lokal, Pendidikan Guru Tanggap Budaya

\begin{abstract}
Teacher education in Indonesia should give more attention to the revitalization of local cultures as the foundation. It is based on the fact that Indonesia is one of the most pluralistic nations in terms of ethnicity and culture. The praxis of culturally responsive teacher education promise solution to bridge the revitalization of local culture and to improve the relevance of teacher education in Indonesian context. Preparing teacher to be a culturally competent teacher can be solutions to marginalization an alienation of many aspects of local culture in Indonesian educational policy.
\end{abstract}

Key words: Teacher Education, Local Culture, Culturally Responsive Teacher Education

\section{Pendahuluan}

It is now widely agreed that teachers are among the most, if not the most, significant factors in children's learning and the linchpins in educational reforms of all kinds. (Cochran-Smith dan Zeichner, 2005: 2).

Kutipan di atas menunjukkan posisi strategis pendidikan guru dalam reformasi pendidikan secara keseluruhan. Setiap negara berlomba melakukan reformasi dalam rangka meningkatkan kualitas guru. Dalam aplikasinya sejumlah negara cenderung mengambil jalan pintas, yakni dengan mengadopsi model pendidikan guru dari negara maju. Sebuah studi menyatakan, pengambil kebijakan pendidikan di kawasan Asia Tenggara dan Asia Timur cenderung melakukan reformasi pendidikan melalui peniruan. Analisis kritis relevansi konsep-konsep tersebut dengan konteksnya jarang dilakukan (Gopinathan, 2006: 261).

Paparan ini berupaya memformulasikan model alternatif pendidikan guru yang berpijak pada kearifan lokal yang sangat kaya di Indonesia. Seruan untuk menata kembali praksis pendidikan guru yang lebih berpijak pada realitas atau konteks sosial budaya semakin nyaring terdengar. Dalam konteks dunia yang semakin kompleks, kapasitas guru yang mampu beradaptasi dengan keragaman peserta didik semakin diperlukan. Mengutip pandangan Gay (2002: 298), "...conventional approaches to teacher education must be decentered and transformed at their most fundamental core, if teachers are to be maximally prepared to teach students of 21st century who will be increasingly racially, culturally, ethnically, socially, and linguistically plurastic." Atau sebagaimana ditegaskan Gopinathan (2006: 262) untuk menghasilkan pendidikan guru yang relevan, efektif dan autentik pijakan konteks sosial budayanya mutlak diperlukan.

Dalam tulisan ini, fokus bahasan diarahkan pada konsep pendidikan tanggap budaya atau dalam literatur disebut: culturally responsive pedagogy, culturally relevant pedagogy, culturally responsive teaching. Diharapkan, paparan ini dapat memicu diskusi lebih intensif dan ekstensif mengenai relasi budaya lokal dan praktik pendidikan secara umum dan pendidikan guru secara lebih spesifik. 


\section{Kajian Literatur}

\section{Pengertian Pendidikan Tanggap Budaya}

Dalam beberapa dekade terakhir, perhatian terhadap relasi budaya dalam berbagai aspek kehidupan semakin menemukan momentumnya. Sebagai makhluk budaya, manusia tidak dapat dipisahkan dari konteks sosio-kultural yang melingkupinya. Meskipun selama beberapa dekade, pandangan positivistik berupaya mereduksi pilihan-pilihan manusia pada pertimbangan logis an-sich, namun realitas menunjukkan kebalikannya. Pilihan-pilihan yang dilakukan manusia pada substansinya merupakan aktualisasi dari pengaruh lingkungan dan perspektif yang melingkupinya. Keputusan mengenai kebermaknaan tindakan misalnya, merupakan hasil simbiosa antara dimensi personal dengan nilainilai sosial yang berlaku. Salah satu gagasan inovatif dalam upaya menjembatani pendidikan dan konteks sosial budayanya tertuang dalam gagasan pendidikan tanggap budaya (culturally responsive/relevant pedagogy).

Culturally Responsive Pedagogy (selanjutnya dipakai singkatan CRP) berpijak pada premise bahwa landasan budaya memainkan peran dalam membentuk gaya belajar dan pada gilirannya menuntut adanya pengajaran yang sejalan dengan lensa budaya tersebut (Villegas, 1991; 13; Provenzo, Ed., 2009: 212). Gagasan mengenai interdependensi atau interkoneksi antara pendidikan dan budaya sesungguhnya bukanlah hal baru. Pendidikan atau lebih khusus lagi institusi pendidikan pada hakikatnya merupakan bagian pranata budaya. Lembaga pendidikan, sebagaimana diulas dalam Encyclopedia of the Social and Cultural Foundations of Education (Provenzo, Ed., 2009), merupakan pengejawantahan dari upaya sadar manusia dalam transmisi dan transformasi budaya. Sejalan dengan hal tersebut, konsep pendidikan tanggap budaya berupaya merevitalisasi berbagai artikulasi budaya, termasuk berbagai aspek kearifan lokal yang berkembang pada setiap komunitas, untuk mendukung terselenggaranya pendidikan yang lebih bermakna.

Sebelum dilanjutkan, dipandang penting melakukan elaborasi mengenai gagasan culturally responsive pedagogy. Elbaz (1993: 190) memaknai istilah responsive sebagai , "... the sense of a large web of interconnections not only among individuals, but among cultures, among natural phenomena, among bio-regions; and between individuals and cultures, between technologies and the life forms they make possible; between language and culture, between culture and schooling." Sementara itu, Irvine $(2003 ; 73)$ menyatakan, "Responsive simply means reacting appropriately in the instructional context. Responsive teachers ... modify their knowledge and training by devoting attention to classroom contexts and individual student needs and experiences." Dari kedua pandangan tersebut, istilah responsif menekankan pada interkoneksi atau keterpaduan langkah guru dalam melaksanakan tugasnya dengan konteks sosial-budaya yang melingkupinya. Eksistensi perbedaan latar belakang keluarga, ekonomi, suku, agama dan kemampuan serta kecenderungan peserta didik tidak dinafikan keberadaannya, sebaliknya guru mendayagunakan perbedaan-perbedaan tersebut sebagai modal untuk mewujudkan harmoni dalam interaksi belajar layaknya seorang konduktor dalam memimpin orkestra musik klasik.

Berikut dikemukakan pandangan penggagas konsep culturally responsive/ relevant pedagogy. Gay (2000: 199) dalam buku Culturally Responsive Teaching: Theory, Research and Practice, mengungkapkan prinsip dasar pendidikan yang responsif adalah terwujudnya kemitraan antara pendidik dan peserta didik, sebagaimana diungkapkannya "we are partners in the quest for learning' and the better we can combine our resources, the better all of us will be. I will teach better and you will learn better." Dalam aktivitas ini, pendidik menempatkan pengalaman, nilai dan persepsi yang berkembang di tengah komunitas sebagai sarana memperkaya praksis pendidikan, "using the cultural characteristics, experiences, and perspectives of ethnically diverse students as conduits for teaching them more effectively" (Gay, 2002: 106; lihat juga Irvine, 2003: 67).

Pendidikan tanggap budaya adalah model pendidikan teoritis yang tidak hanya bertujuan meningkatkan prestasi peserta didik, tetapi juga membantu siswa menerima dan memperkokoh identitas budayanya. Menurut Ladson-Billing (1995: 164) terdapat tiga proposisi pendidikan tanggap budaya, yakni: pertama, peserta didik mencapai kesuksesan akademis; kedua, peserta didik mampu mengembangkan, dan memiliki 
kempetensi budaya (cultural competence): dan peserta didik membangun kesadaran kritis (critical consciousness) sehingga mereka dapat berpartisipasi dalam merombak tatanan sosial yang tidak adil. Ginsberg dan Wlodkowski (2009: 24) dalam Diversity and Motivation: Culturally Responsive Teaching in College menyatakan: Culturally responsive teaching occurs when there is respect for the backgrounds and circumstances of students regardless of individual status and power, and when there is a design for learning that embraces the range of needs, interests, and orientations in a classroom. In other words, an educational system that espouses cultural pluralism also seeks to create learning experiences that protect the knowledge, skill, and experience that learners possess and supports academic attainment and mobility by finding ways for students to develop their strengths.

Berdasarkan paparan tersebut, culturally responsive pedagogy adalah praksis (teori dan aplikasi) pendidikan yang menekankan pada keterkaitan antara pendidikan dan dimensi sosial budayanya. Penekanan pada budaya peserta didik dan komunitas tidak semata dijadikan sebagai upaya mendekatkan peserta didik dengan konteksnya, tetapi lebih dari itu diharapkan dapat menjembatani munculnya kesadaran peserta didik terhadap identitas budayanya. Perbedaan budaya yang sebelumnya dipandang sebagai penghalang prestasi dan interaksi diganti dengan persepsi harmoni yang menempatkan diversitas budaya sebagai kekuatan untuk merangkum perbedaan gaya belajar. Melalui praksis pendidikan tanggap budaya, guru dituntut melakukan elaborasi terhadap berbagai dimensi budaya yang dimiliki peserta didik dan menjadikannya sebagai pijakan dalam memperkaya interaksi pembelajaran.

\section{Landasan Historis Pendidikan Tanggap Budaya dalam Pendidikan Guru}

Sejak tahun 60-an diskursus pendidikan, terutama di Amerika, diramaikan isu kesenjangan dalam pendidikan. Disparitas pendidikan yang ditandai dengan rendahnya prestasi akademis peserta didik yang berasal dari latarbelakang budaya berbeda (Afrika, Amerika Latin, dan keturunan Asia) telah menimbulkan serangkaian perdebatan hangat dikalangan akademisi dan praktisi pendidikan (Banks dan Banks, 1993; Banks, Ed., 2009). Dalam mengatasi persoalan ini, pemerintah meluncurkan berbagai pendekatann. Salah satunya melalui penggagasan dan implementasi pendidikan multikultural (multicultural education) melalui penalokasian anggaran dalam jumlah besar dan melibatkan perguruan tinggi terkemuka di Amerika Serikat (Bennett, 2001; 171).

Dalam penelusuran Banks (2009: 6), pendidikan multikultural yang berkembang tidak saja di Amerika, tetapi meluas di berbagai negara merupakan respon terhadap kegagalan kebijakan pendidikan yang tidak mampu meminimalisir kesenjangan dan berkembangnya sikap tidak bersahabat atau stereotipe terhadap perbedaan ras, agama, dan status kewarganegaraan. Menjawab tuntutan itu, sebagaimana dirangkum Banks (2009: 14), pendidikan multikultural bertujuan memberi kesempatan yang sama (equal opportunity) kepada setiap peserta didik untuk menjadi warga dunia yang aktif. Dalam ungkapannya, Banks menyatakan, "Multicultural education tries to provide students with educational experiences that enable them to maintain commitments to their community cultures as well as acquire the knowledge, skills, and cultural capital needed to function in the national civic culture and community."

Dalam diskursus pendidikan multikultural, berbagai pendekatan dikembangkan (Banks dan Banks, 1993). Salah satu varian pendidikan multikultural menekankan pada penguatan atau keberlanjutan nilai budaya masing-masing kelompok sebagai bagian dari hak asasi (cultural rights) (Benneth, 2001: 175). Dalam perspektif pengusung varian ini, kebijakan publik semestinya memberi ruang akomodasi terhadap keunikan masing-masing budaya, termasuk di dalamnya kearifan lokal yang terdapat pada masyarakat tertentu. Kritik terhadap kebijakan politik yang berupaya menyeragamkan kebijakan pendidikan dengan menafikan eksistensi keragaman budaya, sebagaimana dikampanyekan kalangan asimilasionis dengan gagasan melting pot-nya, semakin menemukan momentumnya pasca menguatnya gerakan-gerakan sipil yang menuntut persamaan hak-hak budaya (cultural rights) (DomNwachukwu, 2010: 62). 
Pada sisi lain, menguatnya tuntutan untuk menghargai identitas budaya lokal juga terkait dengan kekhawatiran mengenai semakin tergerusnya identitas budaya lokal dari generasi muda. Imbas globalisasi yang cenderung mengarah pada homogenisasi dan alienasi budaya lokal. Indigenisasi atau penguatan kembali peran dan fungsi budaya lokal dimaksudkan sebagi alternatif pemecahan kompleksitas persoalan saat ini (Niezen, 2003). Berdasarkan penjelasan tersebut, sebagai pemegang peran strategis dalam proses pendewasaan peserta didik, guru dituntut tidak hanya mentransfer pengetahuan, tetapi dituntut kesadarannya sebagai agen budaya (cultural brokers) yang mempromosikan dan menjadikan dirinya sebagai model dalam perwujudan harmoni di antara keragaman budaya.

\section{Prinsip-prinsip Pendidikan Tanggap Budaya}

Sejak diperkenalkan pada tahun 70-an, berbagai upaya untuk memetakan karakteristik dan prinsipprinsip umum pendidikan tanggap budaya telah dilakukan sejumlah pakar. Meskipun terdapat konsensus mengenai interdependensi antara budaya dan pendidikan sebagai fondasi konsep pendidikan ini, tetapi dalam artikulasi dan tahapan dan implementasi konsep ini muncul perbedaan. Dalam pandangan Gay (2002: 106) terdapat lima elemen esensial dalam pendidikan tanggap budaya, yakni: "developing a knowledge base about cultural diversity, including ethnic and cultural diversity content in the curriculum, demonstrating caring and building learning communities, communicating with ethnically diverse students, and responding to ethnic diversity in the delivery of instruction." Setidaknya terdapat lima panduan atau prinsip aplikasi pendidikan tanggap budaya, yaitu; pentingnya budaya, pengetahuan terbentuk sebagai bagian dari konstruksi sosial, inklusivitas budaya, prestasi akademis tidak terbatas pada dimensi intelektual an-sich, dan keseimbangan dan keterpaduan antara kesatuan dan keragaman (Greer, et.al., 2009; 197). Villegas dan Lucas (2002: 22) ketika membahas mengenai karakteristik guru tanggap budaya mengungkap enam karakteristiknya, yakni: mempunyai kesadaran sosio-kultural; mempunyai afirmasi terhadap keragaman latarbelakang peserta didik; mempunyai kepercayaan diri dalam mengemban tugas; memahami bagaimana peserta didik mengkonstruksi pengetahuan dan mendorong peserta didik mengembangkan konstruksi pengetahuannya sendiri; mengetahui pola hidup peserta didik, dan mampu menggunakan informasi mengenai pola hidup peserta didik untuk mendesain pembelajaran yang bermakna (Villegas dan Lucas, 2002: 22). Dengan demikian, pendidikan guru tanggap budaya tidak hanya bertujuan membekali guru untuk menyadari, menghormati dan mengakui kenyataan bahwa terdapat keragaman budaya atau nilai yang berbeda yang terdapat pada peserta didik yang berasal dari latar belakang suku, agama, bahasa dan etnis yang berbeda, tetapi lebih dari itu mempunyai pengetahuan yang lebih mendalam mengenai sisi-sisi khusus atau keunikan dari budaya peserta didik dan menggunakannya sebagai titik berangkat dalam merencanakan dan melaksanakan pembelajaran (Gay, 2002: 107).

\section{Urgensi Rekonseptualisasi Pendidikan Guru Tanggap Budaya}

Dihadapkan pada perubahan yang sangat cepat di satu sisi dan tuntutan guru sebagai agen budaya yang berfungsi sebagai pelanjut dan pengembang budaya pada sisi lainnya, pendidikan guru dituntut melakukan pembenahan yang berkelanjutan. Tekanan berlebihan pada satu sisi an-sich, akan menimbulkan ketimpanganketimpangan dalam mempersiapkan guru yang dapat menjalankan tugas profesinya. Sehubungan dengan itu, Gopinathan (2006) dalam "Challenging the Paradigm: Notes on Developing an Indigenized Teacher Education Curriculum" mengajukan pertanyaan yang cukup menggelitik, apakah pendidikan guru yang selama ini diterapkan di berbagai negara di Asia sudah cukup responsif terhadap tantangan-tantangan baru dan relevan dengan konteks sosio-kultural yang melingkupinya?

Diperlukan adanya para pemikir yang kritis terhadap praksis pendidikan guru yang selama ini begitu dominan mengadopsi teori-teori pendidikan guru yang diimpor dari negara maju, sehingga kurikulum pendidikan guru lebih akomodatif dan responsif dalam mengintegrasikan nilai-nilai kultural dalam pendidikan. Tidak dapat dipungkiri pandangan mainstream masih memberi 
ruang sangat terbatas bagi tumbuh kembangnya nilai pendidikan yang lebih variatif dan akomodatif terhadap keragaman budaya lokal (Semali dan Kinchelo, 2002; Nakaya, 2004; Trunbull dan Pacheco, 2005). Tantangan lain yang tidak kalah seriusnya berada pada kemampuan lembaga pendidikan tenaga kependidikan (LPTK) dalam melakukan identifikasi nilai-nilai kultural mana saja yang dapat menunjang pendidikan guru yang dapat menghasilkan guru yang mempunyai komitmen sebagai agen budaya. Kenyataannya, penelitian mengenai hal ini masih sangat terbatas. seorang pakar perbandingan pendidikan menyatakan: We do not know very well (in a well documented, empirical sense) what goes on in our classrooms, at the different levels, in the different disciplines, in different regions in our countries. We do not know how effective the teaching strategies we recommend are in the context of the learning challenges faced by pupils in diverse socioeducational environments (Gopinathan, 2006; 278).

Dalam konteks Indonesia, keragaman budaya, etnis, agama, menuntut adanya pendidikan guru yang responsif terhadap kenyataan tersebut. Kacamata kuda yang dimilki guru, yang tidak memberi perhatian pada disparitas budaya peserta didik berdampak pada semakin berjaraknya praktik pendidikan dari realitas sosialnya. Dalam diskursus pendidikan nasional, tokoh-tokoh pendidikan nasional sejak awal kemerdekaan telah menegaskan pentingnya landasan sosial budaya Indonesia yang beragam diakomodir dalam pengagasan dan implementasi kebijakan pendidikan (Dewantara, 1962: 185). Sehingga, keunggulan lokal (local genius) dapat diberdayakan secara optimal. Di akui, sejak beberapa tahun terakhir perhatian ke arah ini mulai mendapat tempat tersendiri dalam diskursus pendidikan nasional. Namun intensitas dan kualitasnya masih perlu ditingkatkan (Kuipers dan Yuleawati dalam Banks, Ed., 2009: 453; Bjork, 2005).

Dalam upaya mempersempit jarak antara praksis pendidikan dengan kondisi aktual di masyarakat, pemerintah sejak tahun 1980-an mengulirkan kebijakan mengenai kurikulum muatan lokal. Melalui muatan lokal, sekolah dan guru diharapkan mampu menjembatani pengalaman aktual peserta didik dengan kondisi riel kehidupannya. Tetapi kenyataannya, muatan lokal cenderung dijalankan tanpa kesadaran mengenai landasan historis serta tuntutan sosial (Drost, 2007; Tilaar, 2007: 221). Kondisi ini terjadi karena ketidakmampuan guru dalam mengembangkan kurikulum muatan lokal pada level interaksi pembelajaran (Bjork, 2004: 252). Nilai-nilai atau tradisi seringkali dipahami sebagai produk yang sudah jadi (Mutakin, 2008: 141). Sehingga, dinamika yang terjadi dalam kebudayaan kurang diperhatikan. Padahal, sebagaimana dikemukakan para ahli, budaya tidaklah statis (Sztompka, 2008: 9; Koentjaraningrat, 2005; Marzali, 2005: 18). Dukungan pemerintah untuk memfasilitasi dan meningkatkan kompetensi guru dalam melaksanakan kebijakan ini belum mencapai taraf semestinya. Dengan kata lain, harapan dan kewenangan yang diberikan pemerintah kepada guru belum dibarengi secara optimal dengan upaya serius dalam meningkatkan kompetensi guru dalam mengaplikasikan kebijakan ini. Padahal sebagaimana ditegaskan Amirrachman, dkk. (dalam Zajda dan Gamage, Ed., 2009: 154) sebuah kebijakan akan efektif apabila disertai persiapan yang baik dan dukungan yang memadai, the policy could have been more effective, if better prepared and supported.

Dalam paparan berikut, dikemukakan bukti mengenai pentingnya reformulasi pendidikan guru sehingga lebih memberi ruang terhadap berbagai kearifal lokal. Sebagai contoh, paradigma konstruktivis dalam psikologi pendidikan misalnya, sebagaimana sedang menjadi trend dalam konsep pelajaran dewasa ini, tidak saja lahir dalam rahim perdaban barat, sehingga nilai-nilai sosio-kultural yang telah melembaga dalam masyarakat tersebut, seperti nilai individualisme dan renggangnya nilai spiritualitas tidak mungkin dapat dipisahkan. Kebebasan individu dalam konteks masyarakat Barat dihadapkan secara diametral dengan nilai kolektivisme yang masih mengakar di sebagian besar negara Asia, misalnya (Gopinathan, 2006: 260). Dalam hal ini, konteks sosial budaya harus dijadikan bahan pertimbangan dalam mempersiapkan guru yang akan menjadi agen budaya atau cultural brokers di lingkungan di mana dia menjalankan tugas profesionalnya (Gentemann dan Whitehead, 1983: 119).

Berbagai literatur dan penelitian mengungkap efektifitas program pendidikan guru semestinya 
meletakkan konteks sosio-kulturalnya sebagai bagian yang penting diperhatikan (Trunbull dan Pacheco, 2005). Sehubungan dengan pentingnya konteks sosio-kultural ini, Gopinathan (2006) mengajak semua pihak lebih kreatif menggali kekayaan kultural dalam konseptualisasi pendidikan guru. Untuk menghasilkan guru yang mempunyai kecakapan atau kompetensi budaya (cultural competent) pendidikan guru memerlukan pembenahan. Sebab, melalui pendidikan guru yang memberi ruang pada dimensi budaya dalam keseluruhan aktivitasnya diharapkan dapat menyemai guru yang sadar dan mempunyai komitmen dalam mengintegrasikan pengetahuannnya tentang budaya di mana dia berada (Leavell, Cowart, dan Wilhelm, 1999: 65). Melalui indegenisasi pendidikan guru, diharapkan guru akan lebih akrab dengan konteks sosiokulturalnya, sehingga lebih responsif terhadap keragaman yang dimiliki peserta didik. Interaksi belajar dan mengajar akan lebih kontekstual dan bermakna, sehingga dapat menjadi modal dalam meningkatkan kualitas penyelenggaraan pendidikan di tanah air.

Pentingnya kearifan lokal dijadikan sebagai salah satu komponen dalam pendidikan guru di tanah air terkait dengan upaya untuk memperluas wawasan dan kompetensi budaya pendidik dalam melaksanakan tugasnya. Selain itu, pemahaman guru yang benar mengenai berbagai dimensi kearifan lokal yang berkembang di tengah-tengah masyarakat membantu guru untuk mengapresiasi kergaman perspektif tersebut, bukan menjadikannya sebagai stereotif yang menyudutkan peserta didiknya. Semali dan Kinchelo (1998: 49) menyatakan, "By encouraging teachers to become familiar with indigenous knowledges, especially knowledges that manifest themselves in local history, traditional stories, and folklore, they will be able to recognize $I K$ and reward the students who bring this form of indigenous literacy to the classroom rather than punishing them."

\section{Simpilan dan Saran Simpulan}

Pendidikan guru tidaklah bersifat bebas nilai (value free), tetapi merupakan aktivitas yang sarat nilai (value laden) dan dipengaruhi konteks sosiokulturalnya. Nilai-nilai sosial tidak mungkin dihilangkan dalam praktek pendidikan, sehingga menjadi tugas semua pihak menggali potensi budaya lokal yang kemudian ditransformasikan baik secara teoritis maupun praktis dalam pendidikan guru. Upaya mengintegrasikan berbagai dimensi kearifan lokal dalam pendidikan guru tidaklah tanpa landasan. Pijakan filosofis, sosiologis, dan paedagogisnya menunjukkan bahwa sinergi antara budaya atau kearifan lokal dengan praksis pendidikan guru merupakan sebuah kemestian. Tantangan globalisasi dengan implikasi-implikasinya menuntut adanya upaya serius untuk menggali kembali khazanah kearifan lokal yang telah diwariskan secara turun temurun. Warisan terpendam tersebut, diharapkan dapat memperluas perspektif pendidik dalam menjalankan tugas profesinya dalam menemukan penyelesaian masalah dalam dunia pendidikan secara lebih mengakar dan kontekstual.

\section{Saran}

Dengan kenyataan semakin tersisihnya kearifan lokal dalam praksis pendidikan di tanah air, diperlukan kerjasama dan kepedulian berbagai pihak untuk melakukan revitalisasi kearifan lokal. Para pengambil kebijakan pendidikan seyogianya memberi ruang dan dukungan lebih nyata kepada para peneliti untuk menggali khazanah kearifan lokal yang tersebar pada berbagai komunitas adat yang terdapat di berbagai penjuru Indonesia. Melalui identifikasi berbagai dimensi kearifan lokal yang relevan dalam menjawab tantangan globalisasi tersebut, lembaga pendidikan guru di tanah air dapat melakukan terobosan-terobosan yang berani untuk mengintegrasikannya dalam praksis kurikulumnya. Melalui sinergi pengambil kebijakan, peneliti dan institusi pendidikan guru, diharapkan upaya melestarikan berbagai kearifan lokal yang telah terbukti memberi kontribusi dalam perwujudan harmoni sosial dapat direalisasikan dalam mewujudkan pendidikan guru berwajah Indonesia. Semoga. 


\section{Pustaka Acuan}

Amirrachman, Alpha., Syafi 'i, Saefudin., Welch, Anthony. 2009. "Decentralising Indonesian Education: The Promise and the Price" dalam Zajda, Joseph, Gamage, David T., Ed. Decentralisation, School-Based Management, and Quality. Netherlands: Springer

Banks, James A. 2009. "Multicultural Education: Dimensions and Paradigm" dalam Banks, James A. Ed. The Routledge International Companion to Multicultural Education. New York: Routledge

Banks, James A., McGee Banks, Cherry A. 1993. Multicultural Education: Issues and Perspectives. Second Edition. Massachusetts: Allyn and Bacon

Benneth, Christine. 2001. "Genres of Research in Multicultural Education" dalam Review of Educational Research, Volume 71, Nomor 02, pp. 171-217.

Bjork, Christopher. 2004. "Decentralisation in Education, Institutional Culture and Teacher Autonomy in Indonesia" dalam Zajda, Joseph., Ed. (2006). Decentralisation and Privatisation in Education: The Role of State. Netherland: Springer

Bjork, Christopher. 2005. Indonesian Education: Teachers, Schools, and Central Bureaucracy. New York: Routledge

Cochran-Smith, Marilyn, Zeichner, Kenneth M. Ed. 2005. Studying Teacher Education: The Report of the American Educational Research Association (AERA) Panel on Research and Teacher Education. New Jersey: Lawrence Erlbaum.

Dewantara, Ki Hadjar. 1962. Karja Ki Hadjar Dewantara: Bagian Pertama, Pendidikan. Yogjakarta: Majelis Luhur Taman Siswa

DomNwachukwu, Chinaka Samuel. 2010. An Introduction to Multicultural Education: from Theory to Practice. Maryland: Rowman dan Littlefield Publishers, Inc

Drost, D.J. 2007. Dari Kurikulum Berbasis Kompetensi (KBK) sampai Manajemen Berbasis Sekolah (MBS): Esai-esai Pendidikan. Jakarta: Penerbit Kompas.

Elbaz, Freema. 1993. "Responsive Teaching: a Response from a Teacher's Perspective." Dalam Journal of Curriculum Studies, Vol. 25, No. 2, pp. 189-199

Gay, Geneva. 2000. Culturally Responsive Teaching: Theory, Research, and Practice. New York: Teachers College Press.

Gay, Geneva. 2002. "Preparing Teacher for Culturally Responsive Teaching" dalam Journal of Teacher Education, Vol. 53, No. 2, hal. 106-116

Gentemann, Karen M., Whitehead, Tony L. 1983. "The Cultural Broker Concept in Bicultural Education" dalam The Journal of Negro Education, Vol. 52 (2), 118-129

Ginsberg, Margery B., Wlodkowski, Raymond J. 2009. Diversity and Motivation: Culturally Responsive Teaching in College, Second Edition. San Fransisco: Jossey-Bass

Gopinathan. 2006. "Challenging the Paradigm: Notes on Developing an Indigenized Teacher Education Curriculum" dalam Improving School Journal http://imp.sagepub.com/cgi/content/ abstract/9/3/261 [on line] di akses tanggal 15 April 2009.

Greer, Bryan., Mukhopadhyay, Swapna. Ed., 2009. Culturally Responsive Mathematics Education. New York: Routledge

Irvine, Jacqueline Jordan. 2003. Educating Teachers for Diversity : Seeing With a Cultural Eye. New York: Teachers College Press

Koentjaraningrat. 2005. Pengantar Antropologi: Pokok-pokok Etnografi II. Cetakan III. Jakarta: Rineka Cipta

Kuipers, Joel C., Yuleawati, Ella. 2009. "Religion, ethnicity, and identity in Indonesian Education" dalam Banks, James A. Ed. The Routledge International Companion to Multicultural Education. New York: Routledge

Ladson-Billings, Gloria. 1995. "Toward Culturally Relevant Pedagogy" dalam American Educational Research Journal, 32(3), 465-491 
Leavell, Alexandra G. , Cowart, Melinda and Wilhelm, Ronald W. 1999. "Strategies for Preparing Culturally Responsive Teachers" dalam Equity dan Excellence in Education, Vol. 32, Nomor 1, hal. 64-71.

Marzali, Amri. 2005. Antropologi dan Pembangunan Indonesia. Jakarta: Kencana

Mutakin, Awan. 2008. Individu, Masyarakat dan Perubahan Sosial. Bandung: Fakultas Ilmu Pendidikan S0sial.

Nakaya, Ayami. 2004. "Muatan Lokal for Current Problems in the Local Community: A Study of the Subject of Local Life and Environmental Education in Jakarta-PLKJ" dalam Pacific Asian Education, Volume 16, Nomor 2. Halaman 38-48.

Niezen, Ronald. 2003. The Origins of Indigenism : Human Rights and The Politics of Identity. Berkeley: University of California Press.

Provenzo Jr, Eugene F. Ed. 2009. Encyclopedia of the Social and Cultural Foundations of Education. California: SAGE Reference Publisher.

Semali, Ladislaus M., Kincheloe, Joe L Ed. 2002. What is Indigenous Knowledge?: Voices from the Academy. New York: Taylor dan Francis e-Library.

Sztompka, Piotr. 2008. Sosologi Perubahan Sosial. Cetakan ke-4, Terjemahan Alimandan. Jakarta: Prenada.

Tilaar, H.A.R. 2007. Mengindonesia, Etnisitas dan Identitas Bangsa Indonesia: Tinjauan dari Perspektif I/mu Pendidikan. Jakarta: Rineka Cipta.

Trunbull, Elise., Pacheco, Maria. 2005. Leading With Diversity: Cultural Competencies for Teacher Preparation and Professional Development. USA: Brown University and Pacific Resources for Education.

Villegas, A.M. 1991. Culturally Responsive Pedagogy for the 1990s and Beyond (Trend Issues Paper No. 6). Washington D.C., Eric Clearinghouse on Teacher Education.

Villegas, Ana María., Lucas, Tamara. 2002. "Preparing Culturally Responsive Teachers: Rethinking the Curriculum" dalam Journal of Teacher Education Volume 53, Nomor 1, hal. 20-32.

Provenzo Jr, Eugene F. Ed. 2009. Encyclopedia of the Social and Cultural Foundations of Education. California: SAGE Reference Publisher.

Semali, Ladislaus M., Kinchelo, Joe L. 2002. "Introduction: What is Indigenous Knowledge and Why we Should Study It?" dalam Semali, Ladislaus M., Kinchelo, Joe L. Ed., What Is Indigenous Knowledge? Voices from Academy. New York: Falmer Press. 